\title{
Length-Weight Relationships of Four Fish Species from Qinzhou Harbor, Guangxi, China
}

\author{
Juan Lei ${ }^{1,}$, , Jianyong $\mathrm{Su}^{1}$, Yongyan Liao ${ }^{1}$, Guorong Cao ${ }^{1}$, Dong Xie ${ }^{2}$, Teng $\mathrm{Wang}^{3}$ \\ ${ }^{1}$ College of Marine Sciences, Beibu Gulf University, Qinzhou, China \\ ${ }^{2}$ Co-Innovation Center for Sustainable Forestry in Southern China, Nanjing Forestry University, Nanjing, China \\ ${ }^{3}$ South China Sea Fisheries Research Institute, Chinese Academy of Fishery Sciences, Guangzhou, China
}

Email address:

leijuanhb@163.com (Juan Lei)

${ }^{*}$ Corresponding author

\section{To cite this article:}

Juan Lei, Jianyong Su, Yongyan Liao, Guorong Cao, Dong Xie, Teng Wang. Length-Weight Relationships of Four Fish Species from Qinzhou Harbor, Guangxi, China. Agriculture, Forestry and Fisheries. Vol. 8, No. 2, 2019, pp. 45-47. doi: 10.11648/j.aff.20190802.13

Received: March 20, 2019; Accepted: April 26, 2019; Published: June 12, 2019

\begin{abstract}
This study determined the total length-weight relationships of the four fish species, Inegocia japonica, Gerres decacanthus, Sillago asiatica, and Evynnis cardinalis, belonging to four families. Fishes were collected using commercial trawls from Qinzhou harbor, China. Samples were collected quarterly from March to December 2017. Total length and weight of each specimen were recorded with an accuracy of $0.1 \mathrm{~cm}$ and $0.1 \mathrm{~g}$, respectively. During the sampling period, a total of 111 fish individuals were collected and measured. The allometric coefficient (b) of length-weight relationship varied from 3.08 for Evynnis cardinalis, 3.17 for Inegocia japonica, 3.18 for Sillago asiatica and 3.19 for Gerres decacanthus. Growth was found as isometric for this four fish species.
\end{abstract}

Keywords: Length-Weight Relationships, Inegocia japonica, Gerres decacanthus, Sillago asiatica, Evynnis cardinalis

\section{Introduction}

The length-weight relationship (LWR) is often used to evaluate the standing stock biomass and is also used to analyze the ontogenetic changes and is also used in the assessment of fish in population dynamic [1]. There are very high number and endemic species of fishes in Chinese Sea [2]. However, biological characteristics of some fish species have seldom been researched. The length-weight relationship (LWRs) is an important tool for management and conservation of fisheries [3-4]. This study provides the first LWRs reports for these four fish species from Qinzhou harbor of China.

\section{Materials and Methods}

Fish samples were collected quarterly from March to December 2017 using commercial trawls from Qinzhou harbor of China. After captured, all specimens were stored on ice and transferred to laboratory. The species were identified according to studies by Lai (2016) [5], Liu (2016) [6] and $\mathrm{He}$ (2013) [7]. For each specimen, the total length was recorded with an accuracy of $0.1 \mathrm{~cm}$, and body weight was measured with $0.1 \mathrm{~g}$ accuracy in Laboratory. The total length was measured with a Vernier caliper from the end of snout to the base of tail. For each species, the length-weight relationships were determined by the function, $\mathrm{W}=\mathrm{aLb}$, where $\mathrm{W}$ is the weight $(\mathrm{g})$ and $\mathrm{L}$ is the total length $(\mathrm{cm})$, was fitted with a simple linear regression model using log-transformed data. The 95\% confidence interval (CI) was determined for parameters "a" and "b" [8]. "a" is the intercept of the regression curve and " $b$ " is the regression coefficients. The best appropriate model was selected based on R2 value [9]. The observed differences were evaluated statistically using SPSS 13.0 and Statistical Analysis System [10].

\section{Results and Discussion}

During the sampling period, a total of 111 fish individuals belonging to four species was collected and measured. Mean total length and weight in four fish species from the Qinzhou harbor is summarized in Table 1. In this study, the total length varied from $88.0 \mathrm{~cm}$ to $196.0 \mathrm{~cm}$ and weight between $3.5 \mathrm{~g}$ to 
$55.5 \mathrm{~g}$, mean total length as $153.5 \mathrm{~cm}$ and weight as $28.7 \mathrm{~g}$ for Inegocia japonica. The total length ranged from $53.0 \mathrm{~cm}$ to $124.0 \mathrm{~cm}$ and weight from $1.6 \mathrm{~g}$ to $28.6 \mathrm{~g}$, mean total length as $91.8 \mathrm{~cm}$ and as $12.1 \mathrm{~g}$ in weight for Gerres decacanthus. The total length oscillated from $78.0 \mathrm{~cm}$ to $178.0 \mathrm{~cm}$, weight from
$3.7 \mathrm{~g}$ to $36.0 \mathrm{~g}$, mean total length as $128.5 \mathrm{~cm}$ and weight as $17.1 \mathrm{~g}$ for Sillago asiatica. For Evynnis cardinalis, the total length ranged from $73.0 \mathrm{~cm}$ to $124.0 \mathrm{~cm}$ and weight from $7.5 \mathrm{~g}$ to $41.6 \mathrm{~g}$, mean total length as $109.2 \mathrm{~cm}$ and weight as $28.7 \mathrm{~g}$.
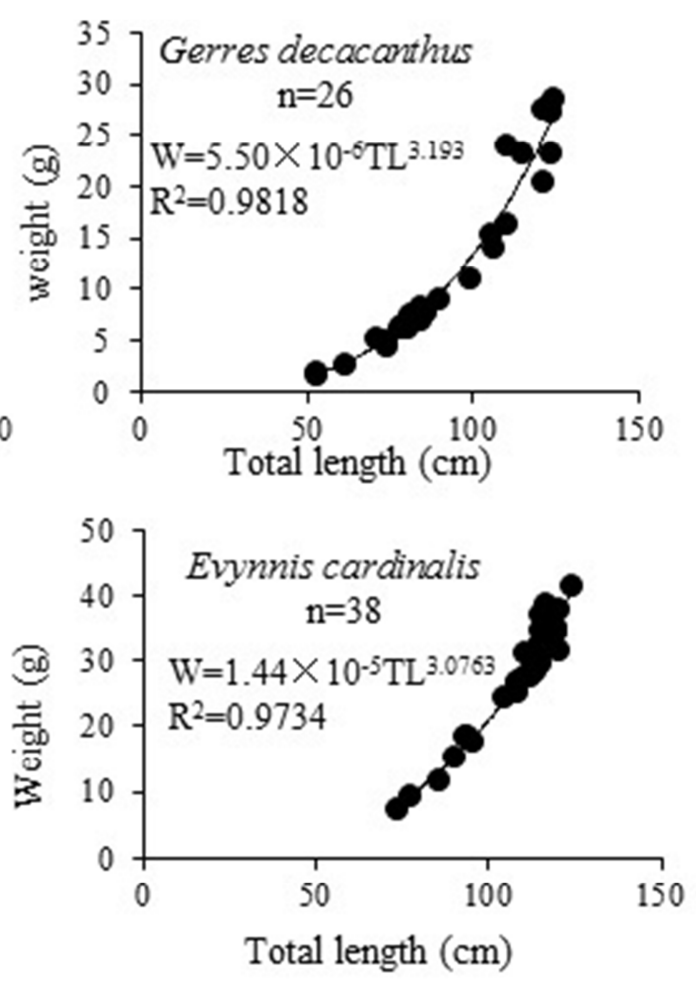

Figure 1. Length-weight relationships of four fish species collected in the Qinzhou haibor.

Table 1. Total length, weight characteristics in four fishes from the Qinzhou harbor.

\begin{tabular}{|c|c|c|c|c|c|c|}
\hline \multirow{2}{*}{ Family } & \multirow{2}{*}{ Species } & \multirow{2}{*}{$\mathbf{n}$} & \multicolumn{2}{|c|}{ Total Length (cm) } & \multicolumn{2}{|l|}{ Weight (g) } \\
\hline & & & Min-Max & Mean \pm SE & Min-Max & Mean \pm SE \\
\hline Platycephalidae & Inegocia japonica (Cuvier, 1829) & 17 & $88.0-196.0$ & $153.5 \pm 8.5$ & $3.5-55.5$ & $28.7 \pm 4.0$ \\
\hline Gerreidae & Gerres decacanthus (Bleeker, 1864) & 26 & $53.0-124.0$ & $91.8 \pm 4.3$ & $1.6-28.6$ & $12.1 \pm 1.7$ \\
\hline Sillaginidae & Sillago asiatica McMay,1982 & 30 & $78.0-178.0$ & $128.5 \pm 5.6$ & $3.7-36.0$ & $17.1 \pm 1.9$ \\
\hline Sparidae & Evynnis cardinalis (Lacepède, 1802) & 38 & $73.0-124.0$ & $109.2 \pm 1.9$ & $7.5-41.6$ & $28.7 \pm 1.3$ \\
\hline
\end{tabular}

Note: n, number of individuals; SE, standard error; Min, minimum; Max, maximum.

Figure 1 shows the relationship between total length and weight of four different fish species sampled during the study, and the regression parameters "a" and " $\mathrm{b}$ ", and the correlation coefficient (R2) are shown in Table 2.

The allometric coefficient "b" of LWRs varied from 3.08 for Evynnis cardinalis, 3.17 for Inegocia japonica, 3.18 for Sillago asiatica and 3.19 for Gerres decacanthus. The values of parameter " $b$ " remained within the expected range of $2.5-$ 3.5 (Froese, 2006). Comparing our results with the Bayesian
LWRs predictions in Fishbase, the "b" values of these four fish species fell within the $95 \%$ confidence intervals of the prediction and were thus not significantly different. Length-weight relationships may change among individuals in different species can be affected by many factors, such as small juvenile specimen, the sample size, size-weight distribution, sampling time, sex, gonad maturity, habitat, season, stomach fullness, diet, the length ranges used, and ecological conditions [11-12].

Table 2. Descriptive statistics and estimated length-weight relationship parameters for four fish species from Qinzhou harbor, China.

\begin{tabular}{llllll}
\hline Species & $\mathbf{n}$ & $\boldsymbol{a}$ & $\boldsymbol{b}$ & $\mathbf{9 5 \%} \mathbf{C I}$ of $\boldsymbol{a}$ & $\mathbf{9 5 \%}$ CI of $\boldsymbol{b}$ \\
\hline Inegocia japonica (Cuvier, 1829) & 17 & 0.00419 & 3.17 & $0.00258-0.0680$ & $3.00-3.35$ \\
Gerres decacanthus (Bleeker, 1864) & 26 & 0.00856 & 3.19 & $0.00572-0.0128$ & $3.00-3.37$ \\
Sillago asiatica McKay, 1982 & 30 & 0.00420 & 3.18 & $0.00283-0.00623$ & $3.02-3.34$ \\
Evynnis cardinalis (Lacepède, 1802) & 38 & 0.0174 & 3.08 & $0.0115-0.0262$ & 0.981 \\
\hline
\end{tabular}

Note: $\mathrm{n}$, sample size; CI, confidence interval; $r^{2}$, coefficient of correlation, Bold, new maximum total length. 


\section{Conclusions}

In terms of fisheries biology and management, it is critical for sustainable ecosystem management of continuous monitoring in nature. Therefore, it is believed that these studies should be carried out to monitor fish resource in the region. In addition, the results of this study will be an important database for future studies of fish species. In general, the study provides basic information on the LWRs of these four fish species, which could useful for sustainable management of fishery in Qinzhou harbor of China.

\section{Acknowledgements}

This research was supported by Guangxi Key Laboratory of Beibu Gulf Marine Biodiversity Conservation, Beibu Gulf University (No. 2019ZB04) and the National Natural Science Foundation of China (No. 31702351; No. 41466003). This project was funded by the Guangxi Natural Science Foundation (GXNSFDA139016), and Guangxi Colleges and Universities Innovation Research Team. This research was also supported by the Major Science and Technology Special Project in Guangxi (AA17204074-3). We wish thank Ling Liyu, Chen Danni, Wu Fu and Lin Meifang for their assistance during the experiment and article preparation.

\section{References}

[1] Lagler, K. F., 1968: Capture, sampling and examination of fishes. In: Methods for assessment of fish production in fresh waters (ed. W. E. Ricker). IBP Handbook No. 3, Blackwell Scientific Publication, Oxford, pp. 7-40.

[2] Xiong, W., Zhu, G. P., Wang, Z. L., Ye, N., 2018. Length-weight relationships of four fish species from mangrove of Zhanjiang, China. J. Appl. Ichthyol., 34, 729-730.
[3] Xiong, W., Tao, J., Zhang, D. C., Liu, C., He, D. K., Chen, Y. F., 2015. Length-weight relationships for four small fish species caught in wetland of central Yangtze River, China. J. Appl. Ichthyol., 31, 219-220.

[4] Xiong, W., Zhu, J., Jin, L., Zhang, J. Q., 2017. Length-weight relationships of seven fish species from the Yuan River of China. J. Appl. Ichthyol., 33, 1240-1241.

[5] Lai, T. H., He, B. Y., 2016: Marine Osteichthyes fishes in Guangxi Beibu Gulf of China. Science Press. pp. 1-453.

[6] Liu, J., Wu, R. X., Kang, B., Ma, L., 2016: Fishes of Beibu Gulf. Science Press. pp. 1-444.

[7] He, B. Y., Lai, T. H., 2013: Marine Fauna in the Mangrove Wetlands of Guangxi Beibu Gulf, China. Science Press. pp. $1-236$.

[8] Froese, R., 2006. Cube law, condition factor and weight-length relationships: history, meta-analysis and recommendations. $J$. Appl. Ichthyol., 22, 241-253.

[9] Ulaş, A. and Aydın, C., 2011. Length-weight relationship of Eriphia verrucosa Forskal (1775) from the Aegean Sea (Linneus, 1758). J. Anim. Vet. Adv., 8: 1061-1062.

[10] Düzgüneş, E., Selimoğlu, A. Ş., Mutlu, C., Şahin, C., Aydın, M., 1998: A preliminary study on the crab species existing on the Trabzon Coasts, Fisheco'98. Trabzon, pp. 520-526.

[11] Oscoz, J., Campos, F., Escala, M. C., 2005. Weight-length relationships of some fish species of the Iberian Peninsula. $J$. Appl. Ichthyol., 21, 73-74.

[12] Froese, R., Tsikliras, A. C., Stergiou, K. I., 2011. Editorial note on weight-length relations of fishes. Acta Ichthyol. Piscat., 41, 261-263. 